\title{
Kernos
}

Revue internationale et pluridisciplinaire de religion grecque antique

$4 \mid 1991$

Varia

\section{G.C. Duranti, Terzo numero binomiale di Euclide e terza civilità di Ammon-Zeus}

Jean Winand

\section{(2) OpenEdition \\ Journals}

Édition électronique

URL : http://journals.openedition.org/kernos/326

DOI : 10.4000/kernos.326

ISSN : 2034-7871

Éditeur

Centre international d'étude de la religion grecque antique

Édition imprimée

Date de publication : 1 janvier 1991

Pagination : 339-340

ISSN : 0776-3824

Référence électronique

Jean Winand, «G.C. Duranti, Terzo numero binomiale di Euclide e terza civilità di Ammon-Zeus », Kernos [En ligne], 4 | 1991, mis en ligne le 11 mars 2011, consulté le 24 septembre 2020. URL : http:// journals.openedition.org/kernos/326 ; DOI : https://doi.org/10.4000/kernos.326 
en cette matière compliquée de la continuité cultuelle durant le moyen âge grec, aux confins brumeux de l'archéologie, de la philologie, de l'anthropologie et de la sociologie. L'A. cependant, habité d'une foi inébranlable, parvient honorablement à proposer des conclusions qui, si elles n'atteignent pas la certitude absolue, apportent de nombreuses et valables conjectures qui tendent à prouver l'origine au moins partiellement mycénienne de nombreux complexes mythico-rituels de nature initiatique. Le livre se présente comme la vérification d'une hypohtèse de base, au travers d'exemples importants que sont les cultes artémisiaques attiques (Brauron-Munychie), béotien (Aulis) et thessalien (Pagasae-Demetriae), les problèmes relatifs aux légendes d'Achille et de Leucippe, des Proetides, de Mélampous, d'Io, des Danaïdes et de plusieurs "histoires brèves" d'Achaïe et d'Arcadie. Bonne bibliographie sélective, index des noms, sujets et auteurs modernes.

S'il est vrai que les filles sont souvent mises à mal dans les légendes initiatiques, les garçons ne le sont pas moins, et il eût été plus opportun sans doute de traiter le problème sans distinction de sexe. De même, certaines légendes, comme celle des Érechthéides, des Cécropides, des vierges locriennes, des filles offertes en pâture aux monstres, auraient pu trouver ici un développement intéressant. Qu'à cela ne tienne, $K$. Dowden nous livre un texte intelligent et qui par son engagement fera progresser notre connaissance des initiations grecques.

Pierre BONNECHÈRE (Louvain-la-Neuve)

Gian Carlo DURANTI, Terzo numero binomiale di Euclide e terza civilità di Ammon-Zeus, Venise, 1988, 1 vol. 19,5 x 28 cm, 455 p.

Cet ouvrage est fondé sur la conviction de l'A. que le cosmos est scandé par de savants accords de principes duels. Le seul moyen de redécouvrir cette harmonie est d'abandonner la logique binaire traditionnelle pour ouvrir une nouvelle voie propre à rendre aux «idées de Justice» la place qui leur revient. Par conséquent, l'A se propose d'ôter à l'algèbre le rôle pilote qui lui est dévolu dans les mathématiques pour réintroduire les valeurs éthiques et esthétiques, substituant à une soidisant "objectivation de la Nature" un idéal de savoir comprenant, dans l'unité immense dont nous faisons partie, l'âme, l'art, la musique, le bien et, finalement, Dieu ! Les mathématiques apparaissent donc ainsi comme une philosophie, comme une conception exhaustive et intégratrice du cosmos.

Il est hélas difficile de suivre aveuglément l'A. sur la voie ambitieuse qu'il s'est tracée, tant ses convictions de départ semblent devoir l'emporter sur ce qu'on pourrait espérer découvrir par une méthode rationnelle. Ainsi, le travail entrepris par la critique moderne d'Euclide est-il balayé d'un trait de plume quand l'A. affirme, comme 
si cela allait de soi, qu'il faut considérer comme authentiques toutes les propositions d'Euclide, même (surtout ?) celles qui sont généralement tenues pour apocryphes.

Beaucoup plus gênante, me semble-t-il, est la certitude, nombre de fois formulée, de l'existence d'une filiation spirituelle directe entre la pensée "mathématico-religieuse» des prêtres égyptiens et la philosophie grecque. C'est ainsi que Platon ne fait qu'unir sa voix aux légendes et aux mythes immortalisés par les prêtres d'Amon dans les temples, et que les Dialogues de Platon, la Métaphysique d'Aristote et les Éléments d'Euclide traduisent en grec cet ensemble de mythes et de légendes.

L'image que l'A. se fait de la civilisation égyptienne est aussi pour le moins curieuse, donnant souvent l'impression de se rattacher aux courants théosophique et symboliste. Ainsi les prêtres égyptiens auraient délibérément caché sous une forme cryptographique, dans une volonté ésotérique, leurs plus belles pensées, position qu'il est impossible de soutenir, même pour les textes ptolémaïques. De même, l'aspect énigmatique de certains monuments ou légendes de l'Égypte devient plus clair, selon l'A., si l'on aborde ceux-ci sous l'angle mathématique. Particulièrement révélateur est l'interprétation symbolique que l'A. donne d'un récit aussi connu que la Bataille de Qadech, où il prend pour argent comptant tout ce que le texte contient de formulaire, sans connaître l'apport pourtant substantiel de la critique moderne. Cela l'amène, entre autres, à voir dans le corps de l'armée d'Amon un principe mathématique dianoétique!

En résumé, par sa méthode éclectique et ses préjugés philosophiques, cet ouvrage n'intéressera peut-être pas tant les spécialistes de l'antiquité ou des mathématiques que les historiens de ces deux disciplines.

Jean WINAND (Liège)

Ana IRIARTE, Las redes del enigma. Voces femininas en el pensamiente griego, Madrid, Taurus Humanidades, 1990, 161 p., 11 images, avec une Préface de Nicole Loraux.

La Préface de Nicole Loraux (Directrice de la thèse de troisième cycle de l'EHESS de Paris qui est le fondement du livre) est sans doute la meilleure présentation de ce livre, qualifié par elle de "stimulant" et "terriblement convaincant".

Dans son introduction (p. 17-35), l'A. fait une révision sommaire des données historiques qui témoignent de la condition marginale de la femme grecque, sans oublier quelques remarques à propos des hétaïres. Par contre, les documents purement littéraires, en commençant par Hésiode, nous offrent un portrait particulier de la femme, avec un lien très étroit entre les activités féminines (p. ex. tisser), sa métis caractéristique et son image extérieure. Mais c'est surtout le théâtre tragique 